\title{
Protective Role of Lycopene Extracted from Tomato (Tomato pomace) against Gamma Irradiation or Carbon Tetrachloride-Induced Brain and Liver Toxicity in Male Albino Rats \\ Hazem, K.A. Sarhan
}

Medical and Radiation Research Department, Nuclear Material Authority, Cairo, Egypt

\begin{abstract}
Background: Based on the effect of substance possessing antioxidant effect previously reported, it was hypothesized that lycopene extracted from tomato (Tomato pomace), a substance possessing antioxidant activity, might be able to protect against oxidative stress induced by either carbon tetrachloride or gamma radiation.

Materials and Methods: A total of 72 experimental male albino rats were randomly divided into equal six groups of twelve rats each. Group 1: served as the control group. Group 2: rats were administrated with (5 gm) tomato extract $/ \mathrm{kg}$ body weight by gastric lavage tube for 15 days. Group 3: rats were exposed to single dose (10 Gy) whole body gamma irradiation. Group 4: rats were administered with $\mathrm{CCl}_{4}$ only in groundnut oil (1:1) at a dose of $3 \mathrm{ml} / \mathrm{kg}$ body weight by single intraperitoneal administration. Group 5: rats were treated with lycopene extract for 15 days before exposure to single dose ( $10 \mathrm{~Gy}$ ) whole body gamma irradiation. Group 6: rats were treated with lycopene extract for 15 days before administered with $\mathrm{CCl}_{4}$ for 15 days.

Results: showed highly significant increase in activities of alanine transferase (ALT), aspartate amino transferase (AST) and alkaline phosphatase (ALP) in serum, 24 hours after $\mathrm{CCl}_{4}$ administration or radiation exposure. Highly significant decrease in activities of superoxide dismutase (SOD), catalase (CAT) and glutathione (GSH) content in the brain tissues. Meanwhile, highly significant increase in MDA content in the brain tissues. Supplementation with lycopene before $\mathrm{CCl}_{4}$ intraperitoneal administration or radiation exposure, exerted marked amelioration of $\mathrm{CCl}_{4}$ and ionized radiation induced disturbances in all the investigated parameters. Histopathological evaluation of the tissues also demonstrated a significant decrease in cellular degeneration and infiltration parameters after lycopene administration. Therefore, lycopene could have a beneficial role in modulating oxidative stress by improving the natural antioxidant mechanism.

Conclusion: Administration of lycopene by using suitable stomach tube pre-CCl${ }_{4}$ intraperitoneal administration or gamma irradiated has significantly ameliorated the disturbances induced in all the investigated parameters.
\end{abstract}

Keywords: Oxidative stress, Brain, Ionizing radiation, $\mathrm{CCl} 4$, lycopene extract, Antioxidant enzymes.

\section{INTRODUCTION}

Carbon tetrachloride $\left(\mathrm{CCl}_{4}\right)$ is a clear, colorless, volatile, heavy and non-inflammable industrial liquid, reportedly used to induce free radical toxicity in different tissues of experimental animals. It can bio-transformed to tri-chloromethylfree radical $\left(\cdot \mathrm{CCl}_{3}\right.$ or $\left.\cdot \mathrm{CCl}_{3} \mathrm{OO}\right)$, thus initiating the chain reaction process ${ }^{(1)}$ which is the most prominent mechanism of $\mathrm{CCl} 4$ in the generation of tissue damage ${ }^{(2)}$. This free radical and related reactive species lead to oxidative stress, which produces major interconnected changes of cellular metabolism, increases the serum marker enzymes, and lipid peroxidation ${ }^{(3)}$.

Injury produced by $\mathrm{CCl}_{4}$ seems to be mediated by reactive metabolite-tri-chloromethyl free radical $\left(. \mathrm{CCl}_{3}\right)$ formed by hemolytic cleavage of tri-chloromethyl per-oxy free radical $\left(\mathrm{Cl}_{3} \mathrm{COO}\right.$.) formed by the reaction of $\mathrm{CCl}_{3}$ with $\mathrm{O}_{2}{ }^{(4)}$, which attach ionic fatty acids in the membranes of endoplasmic reticulum, leading to secondary free radicals, which are subjected to attack by oxygen, and subsequent process, termed lipid peroxidation, which produces damage to membranes and enzymes.

Ionizing radiation provokes the decomposition reaction of water producing a variety of reaction oxygen species (ROS) ${ }^{(5)}$. ROS such as hydroxyl radicals $(\cdot \mathrm{OH})$, super-oxide anion radicals $\left(\mathrm{O}_{2}^{-}\right)$and hydrogen peroxide $\left(\mathrm{H}_{2} \mathrm{O}_{2}\right)$ are extremely reactive and react with the molecule of cell membranes that are composed of a double layer of lipids with proteins dispersed throughout ${ }^{(6)}$. Under normal conditions, there is a balance between the generation of ROS and the cellular antioxidant systems ${ }^{(7)}$. Exposure to ionizing radiation produces significant alterations in the oxidant activity in tissues and causes overproduction of ROS leading to oxidative damage of the lipids, proteins and DNA. The oxidation of polyunsaturated fatty acids in membrane induced by ROS is called lipid peroxidation (LPO). However, organisms have protective systems against ROS, like endogenous antioxidant enzymes. Superoxide dismutase (SOD), glutathione peroxidase (GSH-Px) and catalase 
(CAT) constitute primary enzymatic defense system (8).

However, the cellular antioxidant action is reinforced by the presence of dietary antioxidants ${ }^{(9)}$.

Antioxidants and anti-inflammatory agents play a critical role against $\mathrm{CCl}_{4}$ intoxication and irradiation damage by scavenging active oxygen and free radicals and neutralizing lipid peroxides (10).

Plant food sources contain bioactive compounds that may provide additional health benefits beyond the maintenance of adequate vitamins ${ }^{(11)}$.

Lycopene is one of the most potent antioxidants among dietary carotenoids, found almost exclusively in tomatoes and tomato products and the red pigments of the tomato, exhibits the highest antioxidant activity and singlet oxygen quenching ability of all dietary carotenoids (12) (Fig. 1).

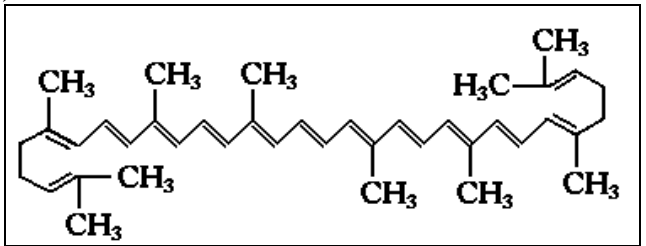

Fig. (1): Structure of lycopene.

So, the aim of the present study was to investigate the possible beneficial effects of lycopene extract on $\mathrm{CCl}_{4}$ and radiation exposure induced acute brain toxicity in rats.

\section{MATERIALS AND METHODS}

\section{Source and preparation of Tomato pomace:}

Tomato pomace including peels, pulp and seeds were obtained from tomato sauce processing line in the factory of Kaha. The pomace was dried by the hybrid solar convective drying system belonging to the Solar Energy Department, National Research Centre, Dokki, Egypt at $30-40{ }^{\circ} \mathrm{C}$, then stored at room temperature $25^{\circ} \mathrm{C}$ for further use.

\section{Extraction and purification of lycopene from tomato pomace:}

Dried tomato pomace was ground for lycopene extraction according to Jamshidzadeh $\boldsymbol{e t}$ al. ${ }^{(13)}$ as follow: The powder was well mixed with diethyl ether $(1: 2 \mathrm{w} / \mathrm{w})$ in a blender for three $\mathrm{min}$. The mixture was then filtered using Bucher funnel. The residue was rinsed with diethyl ether for several times. These rinsing were added to the original extract. The extract was concentrated in a rotary evaporator under vacuum at 50

${ }^{\circ}$ C. Saponification was carried out to remove oils extracted with lycopene. The concentrated extract was washed twice with $200 \mathrm{ml}$ portions of methanolic potassium hydroxide solution $(100 \mathrm{~g}$ potassium hydroxide $+750 \mathrm{ml}$ of methyl alcohol $+250 \mathrm{ml}$ distilled water) in a separating di-hydrogen potassium phosphate solution until the $\mathrm{PH}$ reached 7.5. The aqueous layer was discarded, and the extract was dried over anhydrous sodium sulphate and then was concentrated in a rotary evaporator.

After removal of diethyl ether, the d-limonene was removed from the remaining concentrated crude lycopene by steam distillation, which was carried out at $50{ }^{\circ} \mathrm{C}$ and under $10 \mathrm{~mm} \mathrm{Hg}$ by passing atmospheric steam into the crude lycopene extract. After cooling to room temperature, the mixture was transferred to a separating funnel and a double volume of fresh diethyl ether was added. The aqueous layer was discarded, and the extraction was dried over anhydrous sodium sulphate. The extract was concentrated using of lycopene reached $95 \%$ as assessed by high performance liquid chroma-tography (HPLC). The extracted lycopene then stored at $4^{\circ} \mathrm{C}$ for further use.

\section{Experimental design and biochemical analysis:}

Seventy-two male Swiss albino rats (120-140 g) were used. They were housed in stainless steel cages and kept under the same controlled laboratory conditions of temperature, lighting and ventilation. All of them were fed on standard casein diet and water $a d$ libitum. They were categorized into equal 6 groups each of 12 rats as follows:

Group 1: served as the control group.

Group 2: rats were administrated with (5 gm) tomato extract $/ \mathrm{kg}$ body weight by gastric lavage tube for 15 days ${ }^{(14)}$.

Group 3: rats were exposed to single dose (10 Gy) whole body gamma irradiation. Group 4: rats were administered with $\mathrm{CCl}_{4}$ only in groundnut oil (1:1) at a dose of $3 \mathrm{ml} / \mathrm{kg}$ body weight by single intraperitoneal administration.

Group 5: rats were treated with lycopene extract for 15 days before exposure to single dose (10Gy) whole body gamma irradiation.

Group 6: rats were treated with lycopene extract for 15 days before administered with $\mathrm{CCl}_{4}$.

\section{Biochemical studies:}

After $24 \mathrm{~h}$ of CCl4 injections or whole-body gamma irradiation, animals were sacrificed by slight ether anesthesia. Blood was taken for the separation of serum for the determination of AST, ALT and ALP activities as described by ${ }^{(15,16)}$.

Brain tissues were dissected out for determination of LPO and GSH content, SOD and CAT activities as described by ${ }^{(17,18,19)}$. 
The data were statistically analyzed following the student's test $(\mathrm{t}){ }^{(20)}$.

\section{Histopathological evaluation:}

Brain samples taken from rats were fixed in $10 \%$ formalin for $12 \mathrm{~h}$ and then embedded in paraffin. Five-micron-thick sections were taken from the tissues and stained with hematoxylin and eosin stain. The white matter of the brain tissue was examined in the four groups. Seven parameters were evaluated: hypertrophy in astrocytes, microglial reaction, inflammatory reaction, vascular telangiectasis, endothelial enlargement, edema, and axonal damage.

\section{RESULTS}

Data presented in Table (1) showed that, brain antioxidant parameters of irradiated or $\mathrm{CCl}_{4}$ injected rats showed highly significant decrease compared with their corresponding levels in control group. Meanwhile, LPO showed high significant increase compared with corresponding levels in control group. However, both irradiated and $\mathrm{CCl}_{4}$ injected rats with lycopene pre-treated induced significant improvement.

Data presented in Table (2) showed that, both of groups irradiated and $\mathrm{CCl}_{4}$ induced a high significant increase $(p<0.001)$ in the activities of
AST, ALT and ALP in serum compared to the corresponding levels in control rats. However, groups of lycopene pre-treated either irradiated or $\mathrm{CCl}_{4}$ groups induced significant amelioration for all tested parameters.

\section{Histopathological evaluation of brain}

\section{cortex:}

Control and lycopene groups had normal histomorphologic structure in the brain cortex (Fig. I-2). In the RAD and $\mathrm{CCl}_{4}$ group, astrocytes showed diffuse hypertrophy, numerical increase and light clusters in nuclear chromatin. The microglial cell reaction was diffuse but relatively light. The inflammatory cell reaction was diffuse; in particular, the lymphocyte response was observed. Vascular dilatation, congestion and swelling degeneration in endothelial cells were widely observed. Edema was more prominent, especially around veins, and Rosenthal fibrils were frequently distinguished (Fig. I-12). In the RAD + lycopene and $\mathrm{CCl}_{4}+$ lycopene groups, respectively; hypertrophy in astrocytes became less frequent. Chromatin clusters had disappeared. The microglial cell reaction diluted. The inflammatory cell reaction was milder. Vascular dilatation and endothelial damage were not significant. Edema was milder (Fig. I-14). 


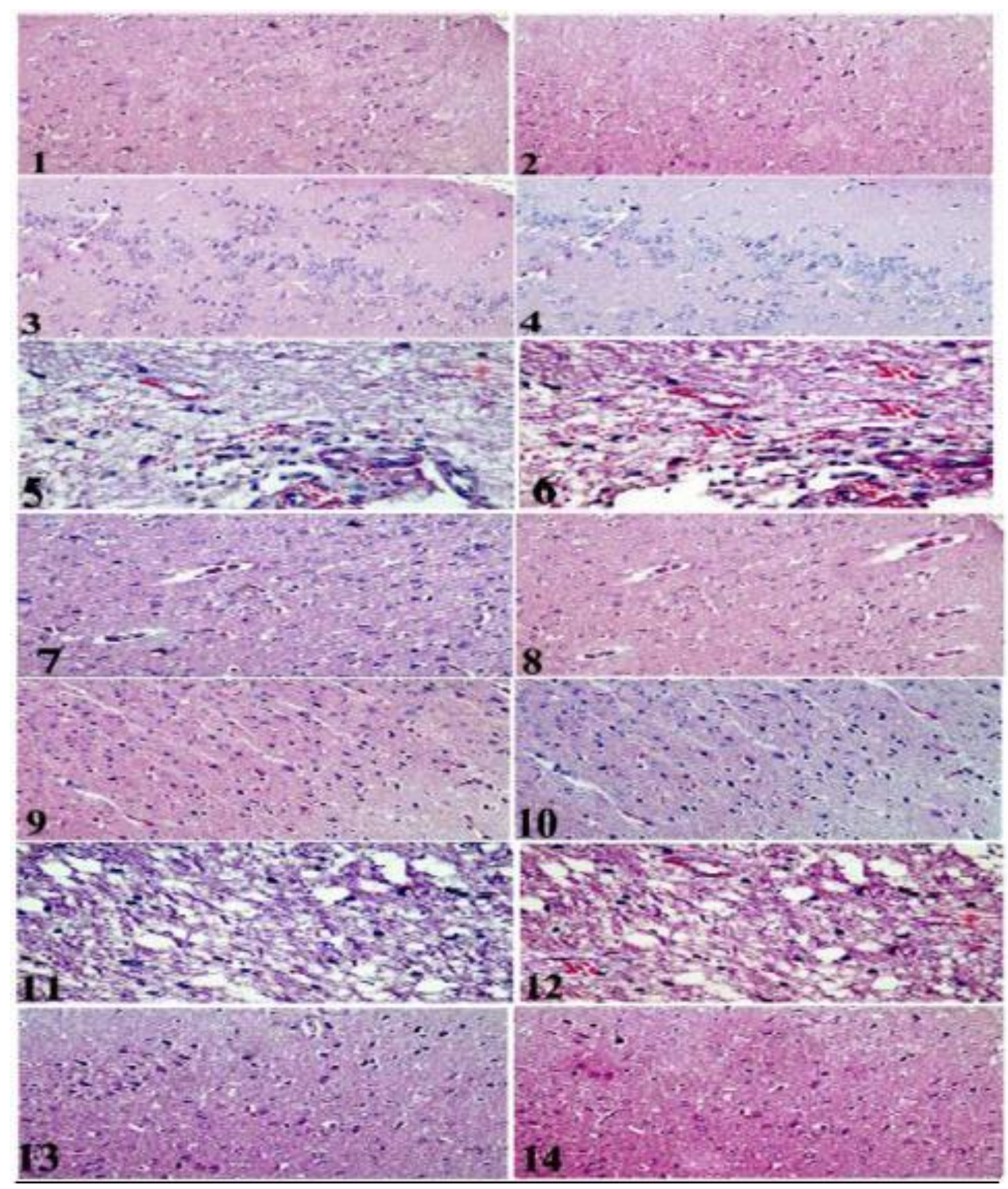

Figure I : Effects of radiation and $\mathrm{CCl}_{4}+$ on brain cortex in $\mathrm{RAD}$ and $\mathrm{CCl}_{4}+$ groups.

[1] Fig. (1\&2): Control and lycopene, groups, respectively had normal histomorphologic structure in the brain cortex. [2] Fig. (3\&4): Astrocytes showed diffuse hypertrophy in RAD and $\mathrm{CCl}_{4}+$ groups, respectively. (H\&E, $\times 400)$. [3] Fig. (5\&6): Vascular dilatation, congestion and endothelial cell enlargement in $\mathrm{RAD}$ and $\mathrm{CCl}_{4}+$ groups, respectively. (H\&E, $\left.\times 400\right)$. [4] Fig. (7\&8) Microglial infiltration in RAD and $\mathrm{CCl}_{4}+$ groups, respectively. (H\&E, $\left.\times 200\right)$. [5] Fig. (9\&10): Inflammatory reaction and congestion in RAD and $\mathrm{CCl}_{4}+$ groups, respectively. (H\&E, $\left.\times 200\right)$. [6] Fig. (11\&12): Edema and prominence of Rosenthal fibers in RAD and $\mathrm{CCl}_{4}+$ groups, respectively. (H\&E, $\left.\times 400\right)$. [7] Fig. (13\&14): showed hypertrophy in astrocytes became less frequent, chromatin clusters had disappeared, the microglial cell reaction diluted, the inflammatory cell reaction was milder, vascular dilatation and endothelial damage were not significant, and edema was milder in $\mathrm{RAD}$ and $\mathrm{CCl}_{4}+$ groups, respectively. 

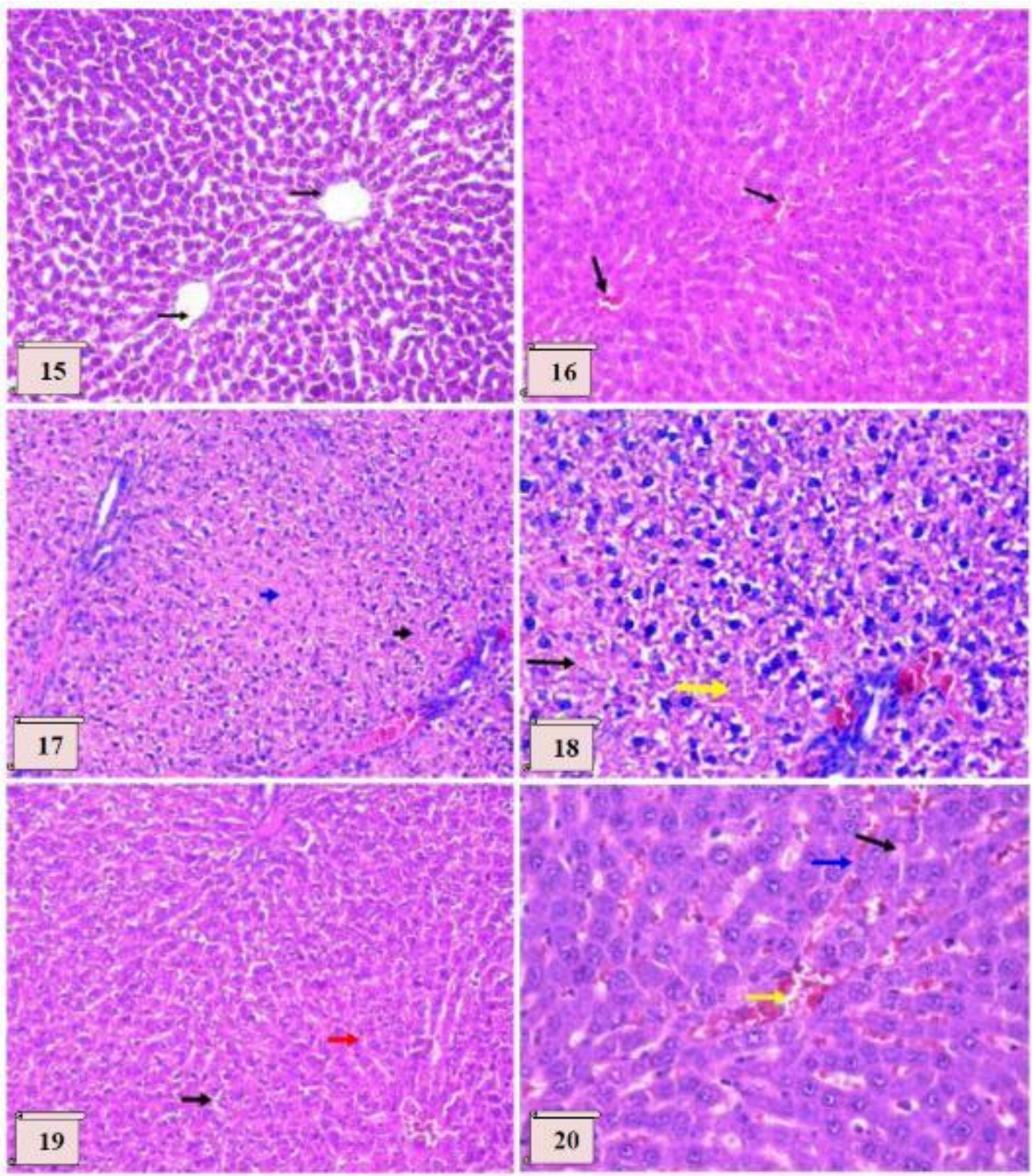

Figure II : Effects of gamma radiation and $\mathrm{CCl}_{4}$ on liver tissues in $\mathrm{RAD}$ or $\mathrm{CCl}_{4}+$ groups.

Fig 15: A liver section from a control rat showing preserved hepatic architecture, hepatocytes are normal, with a central vein (black arrow) (H\&E, x200). Fig. 16: A liver section from lycopene treated rat showing preserved hepatic architecture, hepatocytes within normal, with congested central veins (black arrows) (H\&E, x200). Fig 17: A liver section from 10Gy (S.D) irradiated-rat showing partial loss of hepatic architecture, hepatocytes show mild apoptotic changes (black arrow) and necrotic changes (blue arrow) (H\&E, x200). Fig 18: A liver section from a $\mathrm{CCl}_{4}$ group showing partial loss of hepatic architecture, hepatocytes show mild apoptotic changes (yellow) and necrotic changes (black) (H\&E, x400). Fig 19: A liver section from lycopene +10Gy (S.D) irradiated-rat showing preserved hepatic lobule architecture and mild hydropic degeneration (black arrow) and mild spotty necrosis (red arrow) (H\&E, x200). Fig 20: A liver section from lycopene $+\mathrm{CCl}_{4}$ rat showing preserved lobular architecture, mild hydropic degeneration (black arrow) vessels (yellow arrow) and congestion of sinusoids (blue arrow) (H\&E, x400). 
Histopathological evaluation of liver tissues:

A liver section from a control rat showing preserved hepatic architecture, hepatocytes are normal, with a central vein (black arrow). Fig. II-16: A liver section from lycopene treated rat showing preserved hepatic architecture, hepatocytes within normal, with congested central veins (black arrows). Fig. II-17: A liver section from 10Gy (S.D) irradiated rat showing partial loss of hepatic architecture, hepatocytes show mild apoptotic changes (black arrow) and necrotic changes (blue arrow). Fig. II-18: A liver section from a $\mathrm{CCl}_{4}$ group showing partial loss of hepatic architecture, hepatocytes show mild apoptotic changes (yellow) and necrotic changes (black). Fig. II-19: A liver section from lycopene +10Gy (S.D) irradiated rat showing preserved hepatic lobule architecture and mild hydropic degeneration (black arrow) and mild spotty necrosis (red arrow). Fig. II-20: A liver section from lycopene $+\mathrm{CCl}_{4}$ rat showing preserved lobular architecture, mild hydropic degeneration (black arrow) vessels (yellow arrow) and congestion of sinusoids (blue arrow).

Table.1. Effect of pre-treated lycopene extract on brain antioxidant parameters of irradiated or $\mathrm{CCl}_{4}$ injected rats.

\begin{tabular}{|l|c|c|c|c|}
\hline & $\begin{array}{c}\text { MDA } \\
\text { (nmol/g tissue) }\end{array}$ & $\begin{array}{c}\text { GSH } \\
(\mathrm{mg} / \mathrm{g} \text { tissue })\end{array}$ & $\begin{array}{c}\text { SOD } \\
\text { (U/mg protein })\end{array}$ & $\begin{array}{c}\text { CAT } \\
\text { (U/mg protein) }\end{array}$ \\
\hline Control G. & $53.4 \pm 4.0$ & $59.6 \pm 4.8$ & $52.5 \pm 5.0$ & $55.4 \pm 4.4$ \\
& ---- & ---- & ---- & ---- \\
\hline Lycopene G. & $54.0 \pm 4.4$ & $60.0 \pm 5.5$ & $53.4 \pm 4.7$ & $56.0 \pm 5.0$ \\
& $(+1.1)$ & $(+0.67)$ & $(+1.7)$ & $(+1.0)$ \\
\hline Irr. G. & $95.6 \pm 8.2^{* * *}$ & $18.3 \pm 1.1^{* * *}$ & $30.5 \pm 2.6^{* * *}$ & $32.6 \pm 2.9^{* * *}$ \\
& $(+79.0)$ & $(-69.2)$ & $(-41.9)$ & $(-41.1)$ \\
\hline CCl G. & $89.4 \pm 7.6^{* * *}$ & $15.5 \pm 1.0^{* * *}$ & $27.5 \pm 1.9^{* * *}$ & $28.3 \pm 2.0^{* * *}$ \\
& $(+67.4)$ & $(-73.9)$ & $(-47.6)$ & $(-48.9)$ \\
\hline Lyco. + Irr. & $68.0 \pm 6.0^{*}$ & $50.0 \pm 4.3$ & $48.2 \pm 3.9$ & $43.6 \pm 4.0$ \\
G. & $(+27.3)$ & $(-16.0)$ & $(--8.1)$ & $(-21.2)$ \\
\hline Lyco. $+\mathrm{CCl}_{4}$ & $65.3 \pm 5.8$ & $47.2 \pm 3.8$ & $46.6 \pm 4.0$ & $40.3 \pm 3.5^{*}$ \\
G. & $(+22.3)$ & $(-20.8)$ & $(-11.2)$ & $(-27.2)$ \\
\hline
\end{tabular}

Each value represents the mean of 12 rats \pm SE. Significant different from the corresponding control group at $\mathrm{P}<0.05^{*}, \mathrm{P}<0.01 * *$ and $\mathrm{P}<0.001 * * *$. 
Table.2. Effect of pre-treated lycopene extract on serum liver enzymes of irradiated or $\mathbf{C C l}_{4}$ injected rats.

\begin{tabular}{|c|c|c|c|}
\hline & \multicolumn{3}{|c|}{ SERUM (U/L) } \\
\hline & AST & ALT & $\mathbf{A L P}$ \\
\hline Control G. & $65.5 \pm 5.7$ & $70.3 \pm 6.6$ & $68.6 \pm 6.2$ \\
\hline Lycopene G. & $\begin{array}{c}67.0 \pm 6.0 \\
(+2.2)\end{array}$ & $\begin{array}{c}71.0 \pm 6.5 \\
(+0.9)\end{array}$ & $\begin{array}{c}69.0 \pm 6.3 \\
(+0.58)\end{array}$ \\
\hline Irr. G. & $\begin{array}{c}* * * \\
100.3 \pm 9.5 \\
(+53.0)\end{array}$ & $\begin{array}{c}* * * \\
97.0 \pm 9.0 \\
(+37.9)\end{array}$ & $\begin{array}{c}* * * \\
98.0 \pm 8.6 \\
(+42.8)\end{array}$ \\
\hline $\mathrm{CCl}_{4} \mathrm{G}$. & $\begin{array}{c}* * * \\
111.0 \pm 10 \\
(+69.4)\end{array}$ & $\begin{array}{c}* * * \\
109.0 \pm 9.5 \\
(+55.0)\end{array}$ & $\begin{array}{c}* * * \\
105.0 \pm 9.3 \\
(+53.0)\end{array}$ \\
\hline Lyco. + Irr. G. & $\begin{array}{c}77.3 \pm 6.6 \\
(+18.0) \\
\end{array}$ & $\begin{array}{c}* \\
86.0 \pm 7.8 \\
(+22.3) \\
\end{array}$ & $\begin{array}{c}80.0 \pm 7.3 \\
(+16.6) \\
\end{array}$ \\
\hline Lyco. $+\mathrm{CCl}_{4} \mathrm{G}$. & $\begin{array}{c}* * \\
80.0 \pm 6.5 \\
(+21.9)\end{array}$ & $\begin{array}{c}* * \\
90.2 \pm 7.4 \\
(+28.0)\end{array}$ & $\begin{array}{c}* \\
85.0 \pm 7.2 \\
(+23.9)\end{array}$ \\
\hline
\end{tabular}

Each value represents the mean of 12 rats \pm SE.

Significant different from the corresponding control group at $\mathrm{P}<0.05^{*}, \mathrm{P}<0.01^{* *}$ and $\mathrm{P}<0.001 * * *$.

\section{DISCUSSION}

One of the major reasons for cellular injury after radiation exposure is the generation of free radicals and the possible increased levels of lipid peroxides in the tissues.

Our results revealed that, whole body gamma irradiation of male albino rats at $10 \mathrm{~Gy}$ produced a significant increase in the level of brain MDA, which agreed with ${ }^{(21)}$ who reported that this elevation might be due to inhibition of antioxidant enzyme activities.

After applying (10 Gy) gamma irradiation, the activities of SOD and CAT dropped significantly when compared with control group. In our observation, the significant decrease in both SOD and CAT activities after $10 \mathrm{~Gy}$ gamma irradiation leads to increase in the formation of $\mathrm{O}_{2} \cdot-$ and $\mathrm{H}_{2} \mathrm{O}_{2}$. This decline may be due to inactivation of SOD by $\operatorname{ROS}^{(22)}$.

The data of the present study revealed that administration of $\mathrm{CCl}_{4}$ induced similar changes in the investigated parameters to those exposed to $\gamma$ radiation. Injury produced by $\mathrm{CCl}_{4}$ seems to be mediated by reactive metabolite-tri-chloromethyl free radical $\left(. \mathrm{CCl}_{3}\right)$ formed by the hemolytic cleavage of tri-chloromethylperoxy free radical $\left(\mathrm{Cl}_{3} \mathrm{COO}\right.$.) formed by the reaction of. $\mathrm{CCl}_{3}$ with $\mathrm{O}_{2}{ }^{(23)}$.

This biotransformation is catalyzed by a cytochrome P450-dependent mono-oxygenase to yield tri-chloromethyl and chlorine free radicals. The tri-chloromethyl free radical is then thought to attach ionic fatty acids in the membranes of the endoplasmic reticulum, leading to secondary free radicals within the fatty acids, which is subjected to attack by oxygen, and the subsequent process, which is termed lipid peroxidation, produces damage to membranes and enzymes ${ }^{(24)}$.

Thus the toxicity of $\mathrm{CCl}_{4}$ depends on the cleavage of carbon-chloride bond to generate trichloromethyle free radical $\left(. \mathrm{CCl}_{3}\right)^{(4)}$.

The decline in glutathione content together with increased lipid peroxidation following $\mathrm{CCl}_{4}$ administration were reported by ${ }^{(25)}$.

$\mathrm{CCl}_{4}$ treatment generates free radicals that trigger a cascade of events resulting in liver dysfunction as reflected by significant increase in serum AST, ALT, ALP and $\gamma$-GT activities ${ }^{(26)}$.

Lycopene is a bioactive compound of tomato exerting antioxidant and anti-inflammatory properties, It has been demonstrated that lycopene can inhibit the expression of inflammatory cytokines and reverse the loss of antioxidant enzymes induced by inflammation ${ }^{(27)}$.

Results of the present study showed that rats supplemented with tomato led to improved liver functions as indicated by reduction of liver enzymes and enhancement of antioxidant capacity as indicated by increased glutathione level.

These results are compatible with ${ }^{(13)}$ who reported that tomato supplementation ameliorates biochemical indices and oxidative parameters. In addition (28), has reported that tomato supplementation showed protection indicated by 
return to normal levels of liver transaminases and enhanced antioxidant activity and concluded that the protective nature of tomato may be attributed to its antioxidative property.

In addition, histopathological evaluation of brain tissue was performed. Hypertrophy, microglial reaction, inflammatory reaction, vascular telangiectasis, endothelial enlargement, edema and axonal damage in astrocytes were evaluated. While the brain tissues were normal in the control and lycopene groups, the RAD and $\mathrm{CCl}_{4}$ groups showed diffuse hypertrophy, and numerical increase and mild clustering of nuclear chromatin in the astrocytes. The microglial cell reaction was diffuse but relatively mild. The inflammatory cell reaction was diffuse, and the lymphocyte response was especially observed. Vascular dilatation, congestion and swelling degeneration in endothelial cells were widely observed. Edema was more prominent, particularly around the veins, and Rosenthal fibrils were frequently distinguished.

In the RAD + lycopene and $\mathrm{CCl}_{4}+$ lycopene groups, mild hypertrophy in astrocytes was generally observed. Chromatin clusters had disappeared. The microglial cell reaction became less frequent. The inflammatory cell reaction was milder. Vascular dilatation and endothelial damage were not detected. Edema was milder. In our study, congestion of the lumen of the capillaries with erythrocytes, and a decrease in the frequency of neuronal degeneration in the cerebral cortex also characterized the RAD and $\mathrm{CCl}_{4}$ groups. The most distinctive histological changes after irradiation were vascular telangiectasis, swelling degeneration in endothelial cells, and edema. After radiation, based on these observations, it can be said that vascular systems may be responsible for radiation and $\mathrm{CCl}_{4}$-induced brain damage. This observation needs to be further investigated at a molecular and genetic level. These degenerative

changes in the brain cortex in groups RAD and $\mathrm{CCl}_{4}$ was significantly reduced in the RAD + lycopene and $\mathrm{CCl}_{4}+$ lycopene group. These damages may also vary with radiation and $\mathrm{CCl}_{4}$ volume and exposure time ${ }^{(29)}$. Due to increased permeability of small vessels, these damages cause edema in the brain tissue and migration of the inflammatory cells.

In response to RAD, astrocytes undergo proliferation, exhibit hypertrophic nuclei, and show increased expression of glial fibrillary acidic protein. Conditioned medium from irradiated microglial cells has been shown to induce astrogliosis, which might contribute to radiationinduced edema. However, the exact role of astrocytes in the overall pathogenesis of late radiation-induced brain injury is still unclear, but they are likely to have a contribution by interacting with both vascular and other parenchymal elements in the brain ${ }^{(30)}$.

The data of the present study proved that oral lycopene supplementation ameliorated all the investigated parameters in animals exposed to (10 Gy) single doses of gamma-irradiation or injected with $\mathrm{CCl}_{4}$.

Flavonoids in general and lycopene are free of side-effects, since they are water soluble, any excess lycopene are excreted via sweat or urine. So, lycopene extract can be used safely and effectively in conjunction with other antioxidants plus the minerals ${ }^{(31)}$.

\section{REFERENCES}

1. Adewole S, Ojo S, Adenowo T et al. (2012): Effects of FicusexasperataVahl, (Moraceae) leaf aqueous extract on the renal function of streptozotocin-treated rats. Folia Morphologica, 71: $1-9$.

2. Sahreen S, Khan M. and Khan R (2011): Hepatoprotective effects of methanol extract of Carissa opaca leaves on CCl4- induced damage in rat. BMC Compl Alternative Med., 11: 4852.

3. Bhadauria M, Nirala $K$. and Shukla $S$ (2008): Multiple treatment of Propolisameliorates carbon tetrachloide induced liver injuries in rats. Food Chem.Toxicol., 46: 2703-2712.

4. Slater T F (1982): "Free radicals as reactive intermediates in injury”. In R Synder, DV Parke, JJ Kocsis, DJ Jollow, GG Gebson, CM Witmer, Eds. Biological reactive intermediates II: Chemical mechanisms and biological effects. New York: Plenum. Press., Pp. 575-589.

5. Sandani G, Nadkami GD (1997): Changes in lipid peroxide levels and the activity of reactive oxygen scavenging systems in thyroid tissue after exposure to radioactive iodine in rats. Thyroid, 7: 937-941.

6. Ho Y, Magnenat J, Cargano M et al. (1998): The nature of antioxidant mechanisms: A lesson from transgenic studies. Environ Health Prespect., 106: 1219-1228.

7. Timoth RR, Sharma H M (1991): Free radicals in health and disease. Indian Journal of Clinical Practes, 2: 15-25.

8. Halliwell B, Gutteridge J (1990): Role of free radicals and catalytic ions in human disease, an overview. Metals Enzymology, 186: 1-85.

9. Ghandrasena L, Chackrewarthy S, Perera $\mathbf{P}$ et al. (2006): Erythrocyte antioxidant enzymes in patients with cataract. Ann Clin Lab Sci., 36:201204.

10. Murugesan G,Sathishkumar M, Jayabalani R et al. (2009):Hepatoprotective and alterative 
properties of kombucha tea against carbon tetrachloride-induced toxicity. J. Microbiol.Biotechnol., 19(4):397-402.

11. Howe J, Tanumihardjo S (2006): Carotenoidbiofortified maize maintains adequate vitamin A status in Mongolian gerbils. J Nutr., 136: 25627256.

12. Wood L, Garg M, Powell H et al. (2008): Lycopene rich treatments modify moneosinophilic airway inflammation in asthma: Proof of concept. Free Radic Res., 42: 94-102.

13. Jamshidzadeh A, Baghban M, Azarpira $\mathbf{N}$ et al. (2008): Effects of tomato extract on oxidative stress induced toxicity in different organs of rats. Food Chem Toxicol., 46 (12): 3612-3615.

14. Samaranayake D, Wickramasingle M, Angunawela $P$ (2000): Inhibition of chemically induced liver carcinogenesis in wistar rats by garlic. Phytother Res., 14: 564-657.

15. Reitman S, Frankel S (1957): A colorimetric method of the determination of serum glutamic oxaloacetic and glutamic pyruvic transaminases. Am J Clin Pathol., 28: 56-59.

16. John D, Bauer M (1982): Clinical laboratory methods for the determination of serum alkaline phosphatase". C.V. Mosby Co., USA, 9th ed.: Pp. 580-581.

17. Baker M, Cerniglia G, ZamanA (1990): Microtiter plate assay for the measurement of glutathione disulphate in large number of biological samples. Anal Biochem., 190: 360365.

18. StadtmanE and Oliver C (1991): Metal-catalyzed oxidation of protein. Physiological consequences.J Biol Chem., 266:2005-2008.

19. Aebi H (1984): Catalase in vitro. Methods Enzymol.,105: 121-126.

20. Snedecor W, Cochran G (1980): Statistical methods. 7th edition, Iowa State University Press; Ames, Iowa. https://www.scirp.org/ (S(oyulxb452alnt1aej1nfow45))/ reference/ReferencesPapers.aspx?ReferenceID $=1$ 896667
21. Davydov V, Kisel M, Shdyro O et al. (2000): Chelating and free radical scavenging mechanism of inhibitory action of rutin in lipid peroxidation. Rad Biol Radioecol., 40: 382-386.

22. Guney Y, Bukan N, Dizman A et al. (2004): Effects of two different doses of irradiation on antioxidant system in the liver of guinea pigs. Oncol., 26: 71-74.

23. Weiss S, Evenson J, Thompson K et al. (1996): The selenium requirement for glutathione peroxidase level is half in female rats. J Nutr., 126: 2260-2267.

24. Poli G, Cheeseman K, Biasi F et al. (1989): Promethazine inhibits the formation of aldehydic products of lipid peroxidation but not covalent binding resulting from the exposure of rat liver fractions to CCl4. Biochem J., 264(2):527-532.

25. Lee K, Terada K, Oyadomari S et al. (2004): Induction of molecular chaperones in carbontetrachloride-treated rat liver: implications in protection against liver damage. https://www.ncbi.nlm.nih.gov > pubmed

26. Kus I, Colakoglu N, Pekmez H et al. (2004): Protective effects of caffeic acid phenethyl ester (CAPE) on carbon-tetrachloride-induced hepatotoxicity in rats. Acta Histo Chem., 106(4): 289-297.

27. Reifen R, Nissenkorn A, Matas Z et al. (2004): 5-ASA and lycopene decrease the oxidative stress and inflammation induced by iron in rats with colitis. J. Gastroenterol., 39:514-519.

28. Pal R, Rana S, Vaiphei K et al. (2008): Effect of different doses of carotenoids in isoniazidrifampicin induced hepatotoxicity in rats. Trop. Gastroenterol., 29 (3): 153-159.

29. Yang L, Yang J, Li G et al. (2017): Pathophysiological responses in rat and mouse models of radiation-induced brain injury. Mol Neurobiol., 54:1022-32.

30. Greene-Schloesser D, Robbins ME, Peiffer AM et al. (2012): Radiationinduced brain injury: a review. Front Oncol., 2:73-76.

31. Weiss J, Landauer M (2003): Protection against ionizing radiation by antioxidant nutrients and phytochemicals. Toxicology,189:(1-2):1-20. 